\title{
Fractalkine (CX3CL1) as an amplification circuit of polarized Th1 responses
}

\author{
Paolo Fraticelli, ${ }^{1}$ Marina Sironi, ${ }^{1}$ Giancarlo Bianchi, ${ }^{1}$ Daniele D’Ambrosio, ${ }^{2}$ \\ Cristina Albanesi, ${ }^{3}$ Antonella Stoppacciaro, ${ }^{4}$ Marcello Chieppa, ${ }^{1}$ Paola Allavena, ${ }^{1}$ \\ Luigi Ruco, ${ }^{4}$ Giampiero Girolomoni, ${ }^{3}$ Francesco Sinigaglia, ${ }^{2}$ Annunciata Vecchi, ${ }^{1}$ \\ and Alberto Mantovani ${ }^{1,5}$
}

\author{
${ }^{1}$ Department of Immunology and Cell Biology, Istituto Ricerche Farmacologiche Mario Negri, Milan, Italy \\ ${ }^{2}$ Roche Milano Ricerche Dibit, Ospedale San Raffaele, Milan, Italy \\ ${ }^{3}$ Laboratory of Immunology, Istituto Dermopatico Immacolata, IRCCS, Rome, Italy \\ ${ }^{4}$ Department of Experimental Medicine and Pathology, University of Rome, Rome, Italy \\ ${ }^{5}$ Department of General Pathology, University of Milan, Milan, Italy
}

Address correspondence to: Alberto Mantovani, Istituto di Ricerche Farmacologiche Mario Negri, Via Eritrea 62, 20157 Milan, Italy. Phone: 39-02-39014493; Fax: 39-02-39014596; E-mail: Mantovani@marionegri.it.

Paolo Fraticelli's present address is: Istituto Clinica Medica Generale, Ematologia e Immunologia Clinica, Università di Ancona, Italy.

Received for publication October 9, 2000, and accepted in revised form March 20, 2001.

\begin{abstract}
Fractalkine (FKN, CX3CL1) is a membrane-bound CX3C chemokine induced by primary proinflammatory signals in vascular endothelial cells (ECs). Here we examined the role of FKN in polarized Th1 or Th2 responses. Proinflammatory signals, including LPS, IL-1, TNF, and CD40 ligand, induced FKN, as did IFN- $\gamma$, which had synergistic activity with TNF. IL-4 and IL-13 did not stimulate the expression of FKN and markedly reduced induction by TNF and IFN- $\gamma$. TNF alone or combined with IFN- $\gamma$ also induced release of soluble FKN, which was inhibited by IL-4 and IL-13. In light of this differential regulation of FKN by the master cytokines that control polarized responses, we analyzed the interaction of FKN with natural killer (NK) cells and polarized T-cell populations. NK cells expressed high levels of the FKN receptor CX3CR1 and responded to FKN. CX3CR1 was preferentially expressed in Th1 compared with Th2 cells. Th1 but not Th2 cells responded to FKN. By immunohistochemistry, FKN was expressed on ECs in psoriasis, a Th1-dominated skin disorder, but not in Th2-driven atopic dermatitis. Similarly, ECs in Mycobacterium tuberculosis granulomatous lymphadenitis, but not those in reactive lymph node hyperplasia or in Castelman's disease, showed immunoreactive FKN. These results indicate that regulated expression of FKN in ECs participates in an amplification circuit of polarized type I responses.
\end{abstract}

J. Clin. Invest. 107:1173-1181 (2001).

\section{Introduction}

Chemokines are small secreted proteins involved in the control of leukocyte traffic and inflammation (1-3). Based on a conserved cysteine motif forming disulphide bonds, four families, CXC, CC, C, and CX3C, have been identified. The effects on leukocytes are mediated by seven-transmembrane domain $G$ protein-coupled receptors. There are 18 known functional chemokine receptors that bind multiple chemokines in a subclassrestricted manner. By binding to their receptors, chemokines induce cytoskeletal reorganization and integrin activation followed by migration into tissues.

Fractalkine (FKN, CX3CL1) is a unique, membranebound chemokine, with a transmembrane domain and the chemokine domain on top of a long mucinlike stalk $(4,5)$. FKN shares high homology with the CC family of chemokines, but presents three amino acids between the first two cysteine residues (the CX3C structural motif). The molecule can exist in two forms, membraneanchored or shed soluble glycoprotein, after extracellular proteolysis at a membrane-proximal dibasic cleavage site, similar to cleavage of syndecans. As for the other chemokines, FKN recognizes a Pertussis toxin-sensitive G protein-coupled receptor, CX3CR1 (corresponding to the orphan receptor previously named V28) $(6,7)$. CX3CR1 is capable of inducing locomotion and mobilization of intracellular calcium and activates the heterotrimeric $G$ proteins $(6,8)$, which mediate both leukocyte migration and adhesion. Firm adhesion is not inhibited by Pertussis toxin under static and physiologic flow conditions in monocytes, $\mathrm{T}$ cells, and natural killer (NK) cells $(9,10)$. FKN was initially described as being expressed on IL-1- and TNF-activated endothelial cells (ECs) and having a wide mRNA distribution in human (4) and murine tissues (5).

Chemokines are an important component of polarized type I and type II responses. There is in vitro and in vivo evidence that monocyte chemoattractant protein-1 (MCP-1, CCL2) and macrophage inflammatory protein-1 $\alpha$ (MIP-1 $\alpha$, CCL3) are important for the induction of cytokines involved in polarized responses, such as IL-4 and IL-12 (11-13). Polarized Th1 and 
Th2 populations (characterized by production of IFN- $\gamma$ and IL-4, respectively) were shown to have a different chemokine receptor repertoire (14-16). For instance, Th 1 cells are preferentially attracted by chemokines of the IP10 (CXCL10) family, which are induced by IFN- $\gamma$ and interact with CXCR3 $(2,3)$. Conversely, the CC chemokines macrophage-derived chemokine (MDC, CCL22) and thymus and activation-regulated chemokine (TARC, CCL17) are preferential attractants for polarized Th2 cells that express CCR4 (15). MDC production is induced by IL-4 and IL-13 and inhibited by IFNs and IL-12 (17-21). These studies have outlined the existence of chemokinebased circuits that induce and sustain polarized type I and type II responses $(2,20)$.

The present investigation was designed to assess how cytokines (IFN- $\gamma$, IL-4, IL-13), which induce polarized Th1 (type I) and Th2 (type II) responses (22), affect FKN expression in ECs and how NK cells, a crucial component of Th1 circuits $(23,24)$, and polarized Th1 and Th2 populations respond to FKN. The results obtained define a novel FKN-based amplification circuit of polarized type I responses in vitro and in vivo.

\section{Methods}

Cell culture media and reagents. The following reagents were used for culture of cells: pyrogen-free saline and water (S.A.L.F., Bergamo, Italy); E199 medium and RPMI 1640 (Biochrom KG, Berlin, Germany); and aseptically collected FCS (HyClone Laboratories, Logan, Utah, USA). All reagents contained less than 0.125 endotoxin units per milliliter of endotoxin as checked by the Limulus Amebocyte Lysate assay (Microbiological Associates, Walkersville, Maryland, USA). LPS (from Escherichia coli strain 055:B5) was from Difco Laboratories (Detroit, Michigan, USA).

Cytokines and antibodies. The following human recombinant cytokines were used: IFN- $\gamma$ (Roussel Uclaf, Paris, France), TNF- $\alpha$ (BASF Knoll, Ludwighafen, Germany), IL-1 $\beta$ (Dompè, L'Aquila, Italy), IL-2 (Chiron, Milan, Italy), IL-4 (Schering-Plough, Kenilworth, New Jersey, USA), IL-12 (Hoffmann-La Roche Inc., Nutley, New Jersey, USA), IL-13 (Sanofi Recherche, Labège, France), and FKN (PeproTech EC Ltd., Lo ndon, United Kingdom). J558L cells transfected with the ligand for CD40 (J558L$\mathrm{mCD} 40 \mathrm{~L}$ ) and appropriate controls were used to induce CD40 triggering on ECs (25). The following antibodies were used: polyclonal goat anti-human FKN (R\&D Systems Inc., Minneapolis, Minnesota, USA); rabbit antihuman CX3CR1-purified Ig's (Torrey Pines Biolabs, San Diego, California, USA); rabbit anti-extracellular signal-related kinase 2 (anti-ERK2) polyclonal IgG (Santa Cruz Biotechnology Inc., Santa Cruz, California, USA); anti-IL-4, anti-CD1a, anti-CD34, and anti-CD154 (Pharmingen, San Diego, California, USA); anti-IL-12 clones 17F7 and 20C2 (kindly provided by M. Gately, Hoffmann-La Roche Inc.); anti-factor VIII/vWF (DAKO A/S, Glostrup, Denmark); anti-CD3 and anti-CD4 (Becton Dickinson, Mountain View, California, USA). Anti-
CD6 (clone T12) was purchased from American Type Culture Collection (Manassas, Virginia, USA); antiCD16 (clone B73.1) was a kind gift of G. Trinchieri (Schering-Plough Laboratory, Dardilly, France).

Endothelial cells. Human umbilical vein ECs (HUVECS) were obtained and cultured as described (26). We used routinely confluent cells at 2 nd-6th passage maintained in E199 medium with $20 \%$ FCS, supplemented with endothelial cell growth supplement (ECGS; $50 \mu \mathrm{g} / \mathrm{ml}$; Collaborative Research Inc., Lexington, Massachusetts, USA) and heparin $(100 \mu \mathrm{g} / \mathrm{ml}$; Sigma Chemical Co., St. Louis, Missouri, USA). Human iliac artery ECs (h-IAEs) (27) at 7th passage were grown in E199 medium with supplements as HUVECs and used when confluent. Human dermal microvascular ECs (HDMECs) were obtained from PromoCell GmbH (Heidelberg, Germany) and cultured following the supplier's instructions.

Preparation of NK cells. Leukocytes were obtained from buffy coats of healthy blood donors through the courtesy of Centro Trasfusionale, Ospedale Civile Formalori (Magenta, Italy) by centrifugation on Ficoll-Hypaque gradient (Pharmacia Biotech AB, Uppsala, Sweden). Freshly isolated NK cells were prepared by density gradients on Percoll and purified by depleting $\mathrm{CD} 14^{+}$and $\mathrm{CD}^{+}$cells with Dynabeads (Dynal AS, Oslo, Norway) (28). NK cells were expanded in vitro by coculturing with an irradiated lymphoblastoid cell line, generated in our laboratory (28). After 1 week, proliferating cells were depleted of contaminating $\mathrm{T}$ lymphocytes by panning on anti-CD6-coated plastic. The resulting NK cells were $<2 \% \mathrm{CD}^{+} \mathrm{CD} 14^{+}$and $>80 \% \mathrm{CD}^{2} 6^{+} \mathrm{CD} 56^{+}$. Expanded NK cells were used either as such (resting), after activation with IL-2 $(500 \mathrm{U} / \mathrm{ml})$, or activated on anti-CD16-coated plastic.

Generation of human Th1 and Th2 cells. Human neonatal leukocytes were isolated from freshly collected, heparinized, neonatal blood by Ficoll-Hypaque density gradient centrifugation. Th1 and Th2 cell lines were generated by stimulating neonatal leukocytes with 2 $\mu \mathrm{g} / \mathrm{ml}$ of phytohemagglutinin (PHA) (Wellcome, Beckenham, United Kingdom) in the presence of $2 \mathrm{ng} / \mathrm{ml}$ of IL-12 and $200 \mathrm{ng} / \mathrm{ml}$ of neutralizing anti-IL-4 antibodies for Th1 cultures, or $10 \mathrm{ng} / \mathrm{ml}$ of IL- 4 and 2 $\mu \mathrm{g} / \mathrm{ml}$ of neutralizing anti-IL-12 antibodies $17 \mathrm{~F} 7$ and $20 \mathrm{C} 2$ for Th 2 cultures. Cells were washed on day 4 and expanded in RPMI 1640 with 5\% FCS, 2 mM L-glutamine, $1 \mathrm{mM}$ sodium pyruvate, $100 \mathrm{U} / \mathrm{ml}$ of penicillinstreptomycin (complete medium), supplemented with $100 \mathrm{U} / \mathrm{ml} \mathrm{IL-2}$. Restimulation and intracellular staining for IFN- $\gamma$ and IL-4 (15) confirmed acquisition of the polarized cytokine-production profile. Th1 (ET3.22 and ET3.20) and Th2 (E4.1) clones were generated from adult subjects allergic to Lolium perenne group 1 antigen and are described in ref. 15.

Flow cytometry analysis. Confluent HUVECs $\left(3 \times 10^{5}\right.$ in $\left.9.6 \mathrm{~cm}^{2}\right)$ were kept overnight in E199 medium $+20 \%$ FCS + ECGS and heparin. Medium was then discarded and $1 \mathrm{ml}$ of E199 medium $+20 \%$ FCS and stimuli were added. After 24 hours, FKN expression was stud- 
ied by flow cytometry using a FACStar apparatus analyzing 10,000 events (Becton Dickinson and Co., San Jose, California, USA) (29).

ELISA for soluble FKN. Soluble FKN was measured in ELISA, using polyclonal Ab's from R\&D Systems Inc., following the instructions of the supplier. The sensitivity was $80 \mathrm{pg} / \mathrm{ml}$. Supernatants were obtained from HUVECs incubated in the presence or absence of the different cytokines for 24 hours.

RNA analysis. For Northern blot analysis, total RNA was extracted by the guanidinium thiocyanate method, blotted, and hybridized as described $(30,31)$. Probes were labeled by Megaprime DNA labeling system (Amersham, Buckinghamshire, United Kingdom) with a ${ }^{32} \mathrm{P}-\mathrm{dCTP}(3,000 \mathrm{Ci} / \mathrm{mmol}$; Amersham). Northern blot analysis was performed according to standard procedures. Membranes were exposed for 12-24 hours at $-80^{\circ} \mathrm{C}$ with intensifying screens. RNA transfer to membranes was checked by ultraviolet irradiation, as shown in each figure. FKN cDNA was obtained by amplification with the following oligonucleotides: $5^{\prime}$ ATGGCTCCGATATCTCTGTCGTGGCTG- $3^{\prime}$ as a forward primer and 5'-CGCCATTTCGAGTTAGGGCAGCAGCCTG-3' as a backward primer (GIBCO BRL Custom Primers; Life Technologies, Paisley, United Kingdom). CX3CR1 probe was a gift from P. Gray (ICOS Corp., Bothell, Washington, USA) (32). Densitometric analyses of autoradiographic signals were performed with a scanning densitometric apparatus (Hoeper, San Francisco, California, USA). RNase protection assay (RPA) was performed using the hCR-6 kit, following the manufacturer's instructions (Pharmingen).

Chemotaxis assay. Cell migration was evaluated by using a 48-well microchemotaxis chamber technique (33) with minor modifications $(15,28)$. Briefly, the lower wells of a chemotaxis chamber were filled with chemoattractant solution or assay medium (RPMI 1640 with $1 \% \mathrm{FCS}$ ). A $5-\mu \mathrm{m}$ pore size polyvinylpyrrolidonefree polycarbonate membrane (Nucleopore, Pleasanton, California, USA) coated with fibronectin $(10 \mu \mathrm{g} / \mathrm{ml}$, Sigma Chemical Co.) was layered over the wells, and then the cell suspension $\left(2.5 \times 10^{6}\right.$ to $5 \times 10^{6} / \mathrm{ml}$ in assay medium) was seeded in the upper chamber and incubated at $37^{\circ} \mathrm{C}$ in air with $5 \% \mathrm{CO}_{2}$ for 2 hours. The nonmigrated cells were washed and scraped from the upper surface of the filters, migrated cells were fixed in methanol and stained with Diff-Quik (Dade Behring SpA, Milan, Italy), and the numbers of migrated cells in five high-power fields were counted for each well. The results were expressed as the number of migrated cells per five high-power fields (mean of triplicates \pm SD).

Western blot analysis. Th1 and Th2 cells were lysed in 1\% NP-40 lysis buffer (1\% NP-40; 10 mM Tris pH 8.0; 150 mM NaCl; $1 \mathrm{mM}$ EDTA; $1 \mathrm{mM}$ PMSF; $2 \mu \mathrm{g} / \mathrm{ml}$ each of aprotin, leupeptin, $\alpha-1$ anti-trypsin, and $10 \mathrm{mM} \mathrm{NaF}$ ) and incubated for 15 minutes in ice. Lysates were centrifuged in Eppendorf tubes for 10 minutes at 16,000 g. Fifty milliliters of cleared lysates (equivalent to $1 \times 10^{6}$ cells) were boiled for 5 minutes in reducing Laemmli sample buffer, fractionated by SDS-PAGE, transferred, and immunoblotted with rabbit anti-human CX3CR1 and rabbit anti-ERK2 antibodies followed by horseradish peroxidase-conjugated protein A (Amersham). Detection was performed with an enhanced chemiluminescence detection system (Amersham).

Immunohistochemistry. Six lymph node specimens (two with reactive hyperplasia, two affected by necrotizing granulomatous lymphadenitis with alcohol-acid-resistant Mycobacterium tuberculosis, and two with Castleman's disease, obtained from our pathology department for routine diagnosis) and skin biopsies, obtained after informed consent from healthy adult volunteers $(n=3)$ and from adult patients with chronic plaque psoriasis $(n=4)$ or chronic atopic dermatitis $(n=4)$, were used for the immunohistochemical study. Tissue biopsies were embedded in OCT, snap-frozen in liquid nitrogen, and stored at $-80^{\circ} \mathrm{C}$ until sectioning. For lymph nodes, $5-\mu \mathrm{m}$ cryostat sections were fixed in $100 \%$ acetone, soaked in methanol $1 \% \mathrm{H}_{2} \mathrm{O}_{2}(30 \mathrm{vol})$ for 20 minutes at room temperature to quench endogenous peroxidase activity, washed in PBS, preincubated with goat or rabbit serum for 20 minutes, and sequentially incubated with optimal dilutions of the primary antibodies anti-human FKN and anti-human CX3CR1 (30 minutes). The primary antibodies were respectively resolved with biotinylated anti-goat followed by streptavidin-horseradish peroxidase or LSAB kit (all from DAKO A/S). Each incubation lasted 10 minutes and was followed by a 10-minute wash with PBS. Sections were stained with $0.03 \% \mathrm{H}_{2} \mathrm{O}_{2}$ and $0.06 \%$ diaminobenzidine (DAKO A/S) in PBS for 2-3 minutes. Single stained sections were then washed in tap water and lightly counterstained with hematoxylin, while the sections used for double staining were washed in PBS for 10 minutes and reincubated with the second primary antibodies CD34 or CD1a, resolved with biotinylated anti-mouse and streptavidin-alkaline phosphatase (AP). Each incubation lasted 30 minutes and was followed by a 10 -minute PBS wash. The AP enzyme activity was developed using Naphthol AS-BI phosphate and fast blue RR salt (Sigma Chemical Co.).

For skin biopsies, 4- $\mu \mathrm{m}$ cryostatic sections were kept at $30^{\circ} \mathrm{C}$ for 3 hours, fixed with acetone for 10 minutes, and then treated with $0.3 \%$ hydrogen peroxide to quench endogenous peroxidase activity. Double immunostaining was performed with a goat polyclonal anti-FKN antibody $(15 \mu \mathrm{g} / \mathrm{ml})$ and anti-factor VIII/vWF (1:25) or anti-CD3 (1:50) monoclonal antibody. Sections were also double-stained with a rabbit anti-CX3CR1 (1:100) and anti-CD3, anti-CD4 (1:50), or anti-CD1a (1:25). Avidin-biotin-alkaline phosphatase or avidin-biotin-peroxidase activities (Vector Laboratories, Burlingame, California, USA) were revealed with Blue Vector and 3-amino-9-ethylcarbazole chromogens (Vector Laboratories), respectively. No counterstain was applied. As negative control, primary antibodies were omitted or replaced with an irrelevant isotype-matched antibody or pre immune goat serum. 


\begin{abstract}
Figure 1
Induction of FKN expression in HUVECs by different stimuli. (a) Monolayers of HUVECs were exposed for 24 hours to TNF- $\alpha(20 \mathrm{ng} / \mathrm{ml}), \mathrm{IL}-1 \beta$ $(5 \mathrm{ng} / \mathrm{ml})$, LPS $(100 \mathrm{ng} / \mathrm{ml}), \mathrm{IFN}-\gamma(500 \mathrm{U} / \mathrm{ml})$, IL-13 or IL-4 $(20 \mathrm{ng} / \mathrm{ml})$, and CD40L (J558CD40L-transfected cell line). (b) Monolayers of HUVECs were exposed to TNF- $\alpha(20 \mathrm{ng} / \mathrm{ml})$ or IFN- $\gamma(500 \mathrm{U} / \mathrm{ml})$ for different times, as indicated. RNA was extracted with guanidinium and run in Northern blot analysis. FKN-specific mRNA was detected with cDNA ${ }^{32} \mathrm{P}$-labeled probe. Below the Northern blot is the ethidium bromide-stained $1 \%$ agarose gel that contained the total RNA, before blotting analysis for mRNA. Results are representative of three experiments.
\end{abstract}

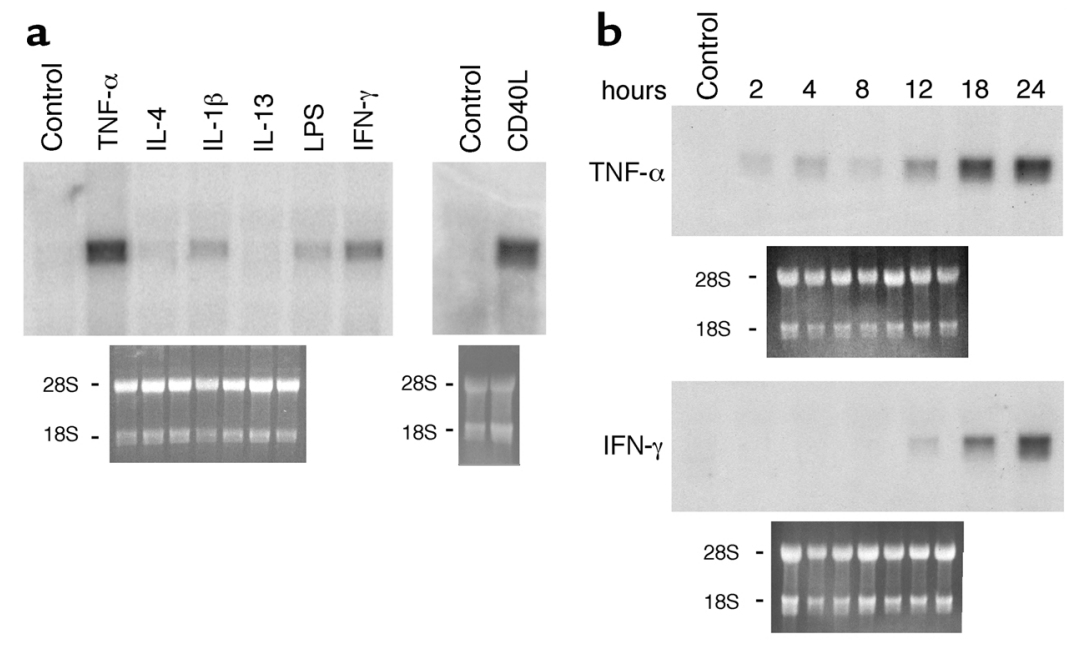

\section{Results}

Induction of FKN by proinflammatory signals including CD4OL and IFN- $\gamma$ and inbibition by IL-4 and IL-13. In a first series of experiments we examined whether master cytokines, which activate type I and type II responses (IFN- $\gamma$, IL-4, IL-13) $(2,20)$ and regulate EC function (34), affect FKN expression in HUVECs. As shown in Figure $1 \mathrm{a}-$ in agreement with previous reports (e.g., refs. 4, 5) - LPS, IL-1, and, most prominently, TNF induced FKN mRNA expression in ECs. These observations were extended to IFN- $\gamma$ and CD40L that increased the steady state levels of FKN transcripts (Figure 1a). J558L control cells did not induce FKN, unlike CD04Lbearing cells, and FKN induction by J558L-mCD40L cells was inhibited in one experiment with anti-CD154 (CD40L) antibodies. In contrast, IL-4 and IL-13 did not stimulate FKN expression (Figure 1a). It should be noted that under these conditions IL- 4 and IL-13 induced a number of responses in ECs (refs. 35-37 and, for review, ref. 34), including, for instance, VCAM-1 expression. For all stimuli, the induction of FKN was time- and dose-dependent (Figure $1 \mathrm{~b}$ and data not shown). For instance, with IFN- $\gamma$ an optimal induction was observed after exposure to $500 \mathrm{U} / \mathrm{ml}$ for 24 hours.

We then examined the effect of cytokine combinations on FKN expression. As shown in Figure 2a, IFN- $\gamma$ and TNF had a synergistic effect in inducing FKN expression. In the experiment shown in Figure 2, densitometric analysis revealed that IFN- $\gamma(50 \mathrm{U} / \mathrm{ml})$ and TNF $(2 \mathrm{ng} / \mathrm{ml})$ induced 4 and 15 densitometric arbitrary units, compared with 63 for the combination. In contrast, IL-13 clearly suppressed FKN induction by IFN- $\gamma$, TNF, or combinations of the two. In a series of three experiments, the inhibition by IL- 13 of FKN expression induced by IFN- $\gamma$ and TNF was $75 \pm 3 \%$. IL-13 also blocked LPS-induced FKN expression (Figure 2a). Similar results were obtained with IL-4, as shown in Figure 2b.

Effect of cytokines on FKN surface expression and release. We then examined the effect of cytokines on FKN surface expression in ECs. A series of four (for IL-13) and two (for IL-4) experiments was conducted with a polyclonal
anti-FKN antiserum. As shown in Figure 3, TNF and IFN- $\gamma$ induced surface expression of FKN. As expected on the basis of transcript analysis, IFN- $\gamma$ and TNF had a synergistic action on FKN membrane levels in ECs. For instance, suboptimal concentrations of TNF (2 $\mathrm{ng} / \mathrm{ml})$ and IFN- $\gamma(50 \mathrm{U} / \mathrm{ml})$ had a barely detectable effect per se (not shown), whereas the two combined induced strong FKN expression (Figure 3). IL-13 (Figure 3a) and IL-4 (Figure 3b) almost completely inhibited TNF-induced $(20 \mathrm{ng} / \mathrm{ml})$ and IFN- $\gamma$-induced (500 $\mathrm{U} / \mathrm{ml}$ ) FKN surface expression. The inhibitory activity was also significant, but not complete, when the TNF + IFN- $\gamma$ combination was used, particularly when high doses of the two inducers were used. ECs from iliac arteries and dermal microvessels (h-IAEs and HDMECs) were also used in a limited series of experiments. In both cell preparations, TNF in combination with IFN- $\gamma$ induced expression of FKN at levels similar to those seen in HUVECs (data not shown).

$\mathrm{FKN}$ is a transmembrane protein that can undergo proteolytic cleavage with release of a soluble, biologically active form of this chemokine (4). It was therefore important to assess how individual cytokines, and combinations thereof, affected FKN release. As shown in Table 1, TNF induced appreciable levels of FKN release $\left(390 \pm 105 \mathrm{pg} / \mathrm{ml} / 10^{5} \mathrm{ECs}\right.$ in 24 hours at a TNF concentration of $20 \mathrm{ng} / \mathrm{ml}$; mean $\pm \mathrm{SD}$ of four experiments). In contrast, FKN was undetectable in the supernatant of IFN- $\gamma$-stimulated cells (five experiments). As expected on the basis of FACS analysis, IFN- $\gamma$, though inactive per se in inducing FKN release, significantly increased the TNF-induced shedding (80\% mean increase over TNF alone for $2 \mathrm{ng} / \mathrm{ml} \mathrm{TNF}$ and $50 \mathrm{U} / \mathrm{ml} \mathrm{IFN- \gamma}$ in a series of two experiments). IL-4 and IL-13 completely blocked the release induced by both concentrations of TNF. When TNF and IFN- $\gamma$ were combined at a concentration of 20 $\mathrm{ng} / \mathrm{ml}$ and $500 \mathrm{U} / \mathrm{ml}$, IL-4 and IL-13 caused a $48 \pm 13.9 \%$ (three experiments) and $84.6 \pm 21.7 \%$ (two experiments) inhibition, respectively.

CX3CR1 expression and responsiveness to FKN of NK cells and polarized Th cells. The differential effects of IFN- $\gamma$ ver- 
Figure 2

Inhibition of induction of FKN mRNA expression in HUVECs by IL-13 and IL-4. Monolayers of HUVECs were exposed for 24 hours to the stimuli indicated or their combination. Cytokine concentrations were: IL-13 and IL-4, $20 \mathrm{ng} / \mathrm{ml}$; LPS, 100 $\mathrm{ng} / \mathrm{ml}$; TNF- $\alpha, 2$ (a) and 20 (b) $\mathrm{ng} / \mathrm{ml}$; IFN- $\gamma, 50(\mathbf{a})$ and $500(\mathbf{b}) \mathrm{U} / \mathrm{ml}$. Results are representative of three experiments for IL-13 and two experiments for IL-4. a

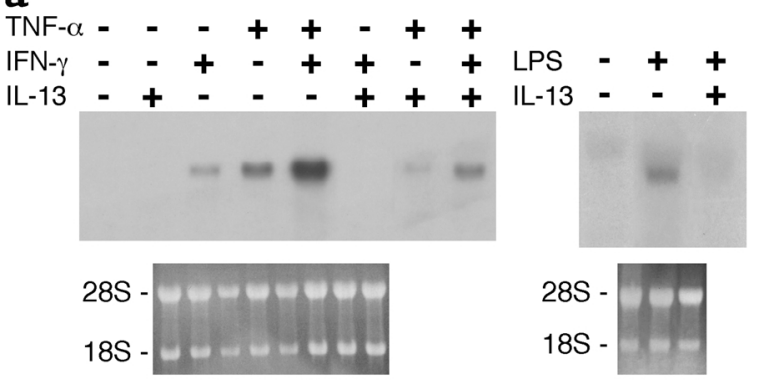

b

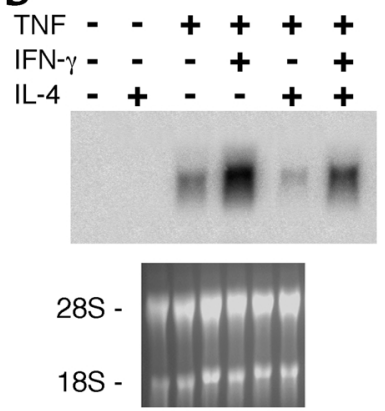

sus IL-13 and IL-4 on FKN expression in ECs raised the possibility that this molecule may attract cells involved in polarized T-cell responses differentially. To test this possibility, we first examined expression of the FKN cognate receptor CX3CR1 in NK cells (three experiments) and polarized $\mathrm{CD}^{+}$populations (two experiments). As shown in Figure 4a, CX3CR1 was strongly expressed in $\mathrm{NK}$ cells in agreement with previous results $(8,38)$. Interestingly, engagement of the activating receptor CD16 caused a drastic downregulation of CX3CR1 expression in NK cells. CX3CR1 mRNA was also detectable in polarized Th1 cells, though at much lower levels than in NK cells. Transcript levels were barely detectable in polarized Th2 cells. Similar results were obtained in polarized antigen-specific clones generated from adult donors (Th1 clones ET3.20 and ET3.22 and Th2 clone E4.1; Figure 4a). Accordingly, FKN receptor was expressed in Th1 but not in Th2 cells as assessed by Western blotting. As expected on the basis of receptor expression, a soluble version of FKN induced migration of NK cells and Th1 cells but not of Th2 cells (Figure 4b).
Differential expression of FKN in vivo. The results discussed above suggested that EC-expressed FKN might be part of an amplification loop of polarized type I responses. To gain insight into the expression of FKN in pathologic lesions characterized by a prevalent Th1 or Th2 response, psoriasis and atopic dermatitis lesions were examined. Psoriasis is a chronic skin disease characterized by hyperproliferation of keratinocytes and the presence of an inflammatory infiltrate consisting of activated Th1 cells, dendritic cells, monocytes, and neutrophils. The T-cell infiltrate precedes and causes the epidermal hyperplasia through the release of mediators, primarily IFN- $\gamma(39,40)$. Atopic dermatitis is an eczematous skin disease belonging to the atopic disorders, where initiation of the lesions is associated with a predominant infiltration of dendritic cells and Th2 lymphocytes $(41,42)$. The anti-FKN antibody marked intensely the majority of vessels in the papillary dermis in psoriasis (Figure $5 \mathrm{~b}$ ), whereas only very few vessels were stained in atopic dermatitis (Figure 5a). Costaining for factor VIII and CD3 confirmed that the anti-

\section{Figure 3}

Inhibition of induction of FKN surface expression by IL-13 and IL-4. Monolayers of HUVECs were exposed for 24 hours to TNF- $\alpha$ (2 or 20 $\mathrm{ng} / \mathrm{ml})$ and IFN- $\gamma(50$ or 500 $\mathrm{U} / \mathrm{ml}$ ) and their combination in the presence (white area) or absence (gray area) of IL-13 $(20 \mathrm{ng} / \mathrm{ml})(\mathbf{a})$ or IL-4 (b). FKN expression was evaluated by FACS analysis after staining the cells with a goat polyclonal anti-FKN antibody. Results are representative of four experiments for IL-13 and two experiments for IL-4. The low doses of IFN- $\gamma(50 \mathrm{U} / \mathrm{ml})$ and TNF- $\alpha(2 \mathrm{ng} / \mathrm{ml})$ as individual agents had little effect and are not shown for simplicity.
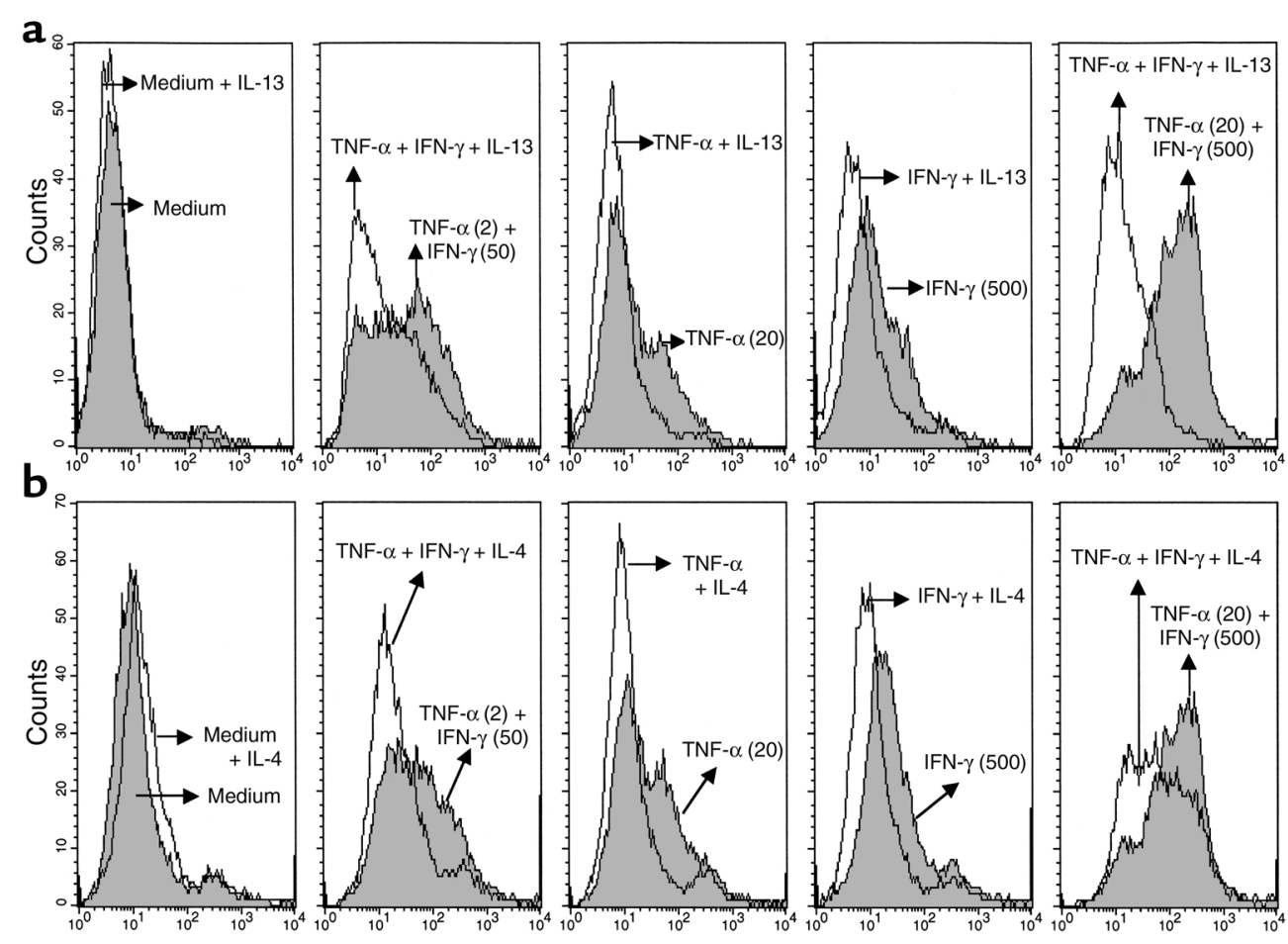

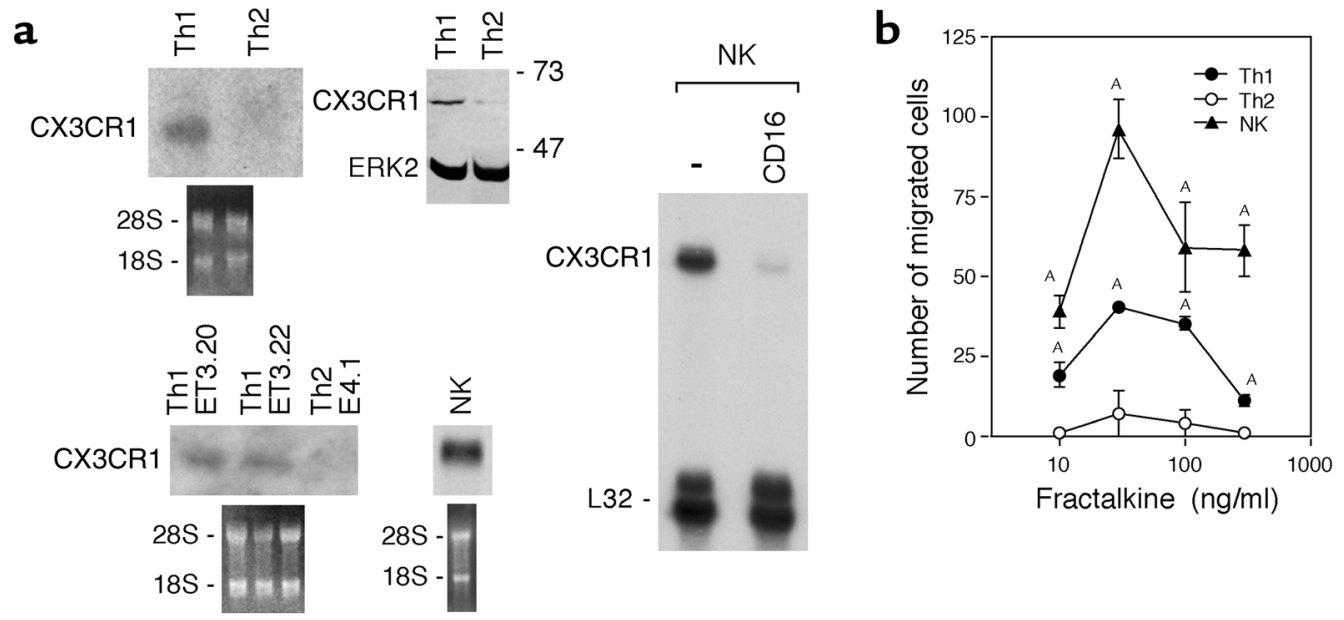

\begin{abstract}
Figure 4
Expression of CX3CR1 and chemotactic responsiveness of NK cells, Th1 cells, and Th2 cells. (a) Upper part: mRNA expression of CX3CR1 evaluated in NK cells and in polarized Th 1 and Th 2 cells by Northern analysis. The receptor protein was evaluated by Western analysis with a rabbit polyclonal antibody; ERK2 was detected as described in Methods and served as a loading standard. Lower part: $m$ RNA expression of CX3CR1 was evaluated in Th1, Th2, and NK cells by Northern analysis. Modulation of mRNA CX3CR1 in NK evaluated in RPA is shown in the right part. Results are representative of three experiments for NK cells and of two experiments for polarized Th1/Th2 preparations; data on adult clones are shown. (b) Chemotactic migration to FKN of Th1, Th2, and NK cells. Results are mean \pm SD of triplicates; ${ }^{A} P<0.01$ vs. medium by Dunnett's test.
\end{abstract}

FKN antibody stained ECs, and not the perivascular lymphocytes. In addition, in both psoriasis and atopic dermatitis suprabasal keratinocytes showed a uniform anti-FKN immunoreactivity. Normal skin from healthy individuals was always negative for FKN in both the dermis and the epidermis. To extend these observations to another Th1-dominated response, lymph nodes affected by $M$. tuberculosis granulomatous lymphadenitis were studied. FKN was expressed by the ECs of the majority of the vessels of the remaining parenchyma among the granulomas (Figure 6a). Staining with anti-CD34 confirmed the endothelial nature of FKN-positive cells (Figure 6b). In these nodes, dendritic-like cells of the paracortical areas were FKN-positive (Figure 6c). In human lymph nodes affected by non-Th1-dominated diseases such as reactive hyperplasia or Castleman's disease, ECs were negative for FKN and FKN-positive cells were confined to the $\mathrm{T}$ cell-dependent paracortical area and had dendritic morphology (not shown).

A polyclonal anti-CX3CR1 antiserum was used to examine receptor expression in lesional skin. CX3CR1 immunostaining was localized in a limited fraction (10-20\%) of dermal infiltrating cells in both psoriatic and atopic dermatitis lesions. No substantial differences in the number and distribution of CX3CR1 $1^{+}$cells were observed between the two diseases. CX3CR1 staining colocalized with a small fraction of $\mathrm{CD}^{+}$and $\mathrm{CD}^{+}$ $\mathrm{T}$ cells and not with $\mathrm{CD} 1 \mathrm{a}^{+}$dendritic cells (Figure 5, e-g, and data not shown). CX3CR $1^{+}$cells were absent in control skin from healthy donors. Immunostaining with anti-CX3CR1 of the parenchymal area among the granulomas of $M$. tuberculosis lymph nodes showed staining of cells with macrophage-like morphology and some lymphocyte-like cells (Figure 6d).

\section{Discussion}

The results presented here show that the various signals that activate ECs, including IFN- $\gamma$ and CD40L, induce FKN mRNA and protein expression in human ECs. Therefore the present observations extend to these activation signals previous findings originally obtained with IL-1, TNF, and LPS $(4,5,43)$. Moreover, when IFN- $\gamma$ was combined with TNF (or in preliminary experiments with LPS, not shown), the response observed was more than additive. In contrast, IL-4 and IL-13 did not induce FKN expression and suppressed its induction. These results demonstrate that IFN- $\gamma$ and IL-4/IL-13, which activate polarized Th1 and Th2 responses, respectively, have divergent effects on FKN expression in ECs.

ECs express a non- $\gamma$ chain containing IL-4/IL-13 receptor complex, and these cytokines activate a dis-

\section{Table 1}

Modulation of soluble FKN release by IL-4 and IL-13 in HUVECs

\begin{tabular}{lccc}
\hline Treatment & \multicolumn{3}{c}{ Soluble FKN $(\mathrm{pg} / \mathrm{ml})$} \\
& Medium & IL-4 & IL-13 \\
Control & Undetec. & Undetec. & Undetec. \\
TNF- $\alpha(20 \mathrm{ng} / \mathrm{ml})$ & $240 \pm 40$ & Undetec. & Undetec. \\
IFN- $\gamma(500 \mathrm{U} / \mathrm{ml})$ & Undetec. & Undetec. & Undetec. \\
TNF- $\alpha(20)+\mathrm{IFN}-\gamma(500)$ & $780 \pm 70$ & $395 \pm 10^{\mathrm{A}}$ & $240 \pm 10^{\mathrm{A}}$ \\
TNF- $\alpha(2 \mathrm{ng} / \mathrm{ml})$ & $200 \pm 2$ & Undetec. & Undetec. \\
IFN- $\gamma(50 \cup / \mathrm{ml})$ & Undetec. & Undetec. & Undetec. \\
TNF- $\alpha(2)+\mathrm{IFN}-\gamma(50)$ & $250 \pm 1$ & $105 \pm 1^{\mathrm{A}}$ & Undetec.
\end{tabular}

Confluent HUVECs were cultured for 24 hours with medium or with the different cytokine combination reported. IL-4 and IL-13 were used at $20 \mathrm{ng} / \mathrm{ml}$. Soluble FKN was measured in a sandwich ELISA assay; the sensitivity was $80 \mathrm{pg} / \mathrm{ml}$. Results are presented as mean \pm SD of triplicate samples and are representative of three experiments for $20 \mathrm{ng} / \mathrm{ml} \mathrm{TNF}-\alpha$ and $500 \mathrm{U} / \mathrm{ml} \mathrm{IFN-} \gamma$ and of two experiments for $2 \mathrm{ng} / \mathrm{ml} \mathrm{TNF}-\alpha$ and $50 \mathrm{U} / \mathrm{ml} \mathrm{IFN- \gamma}$. Undetec., undetectable, $<80$ $\mathrm{pg} / \mathrm{ml}$. ${ }^{A} P<0.01$ by Dunnett's test vs. cells treated with TNF- $\alpha$ and IFN- $\gamma$. 
tinct functional program in vascular cells (34). This includes induction or costimulation of IL-6 and of chemokines, such as MCP-1 (CCL2) and eotaxin (CCL11), as well as induction of the adhesion molecule VCAM-1 with concomitant suppression of E-selectin and ICAM-1 (34-37). FKN is a transmembrane chemokine that can be released by proteolytic cleavage. In addition, FKN can bind its cognate receptor CX3CR1 and act as an adhesion molecule independently of post-receptor signaling events $(2,6,10)$. The results presented here show that inhibition of FKN is part of the differential regulation by IL-4/IL-13 of adhesion molecules and chemokines in ECs.

FKN can be shed after extracellular proteolysis at a membrane-proximal dibasic cleavage site (4). TNF induced membrane expression and shedding of FKN, whereas IFN- $\gamma$, at comparable levels of surface expression, caused little or no shedding. IL-4 and IL-13 inhibited FKN release as they did for surface expression. The capacity of TNF, but not of IFN- $\gamma$, to cause FKN release is reminiscent of its capacity to induce matrix metalloproteinase-mediated shedding of other membrane receptors, such as the TNF receptors themselves and the IL-1 type II decoy receptor $(44,45)$. The relative importance of membrane-bound versus released FKN in leukocyte recruitment remains to be determined.

Cells other than ECs express FKN either constitutively or upon stimulation (46-49). Papadopoulos et al. analyzed normal human skin for FKN expression and found that many CD1 $\mathrm{a}^{+}$cells (Langerhans cells) were also FKN-positive (46). In addition, melanocytes, present along the basement membrane zone, were stained by the anti-FKN antibody. In contrast to these results, we did not observe FKN-positive cells within the epidermis of normal human skin, a finding probably related to the different antibody used. By immunohistochemistry we found that FKN was prominently expressed by dendritic cells in lymph nodes. Moreover,

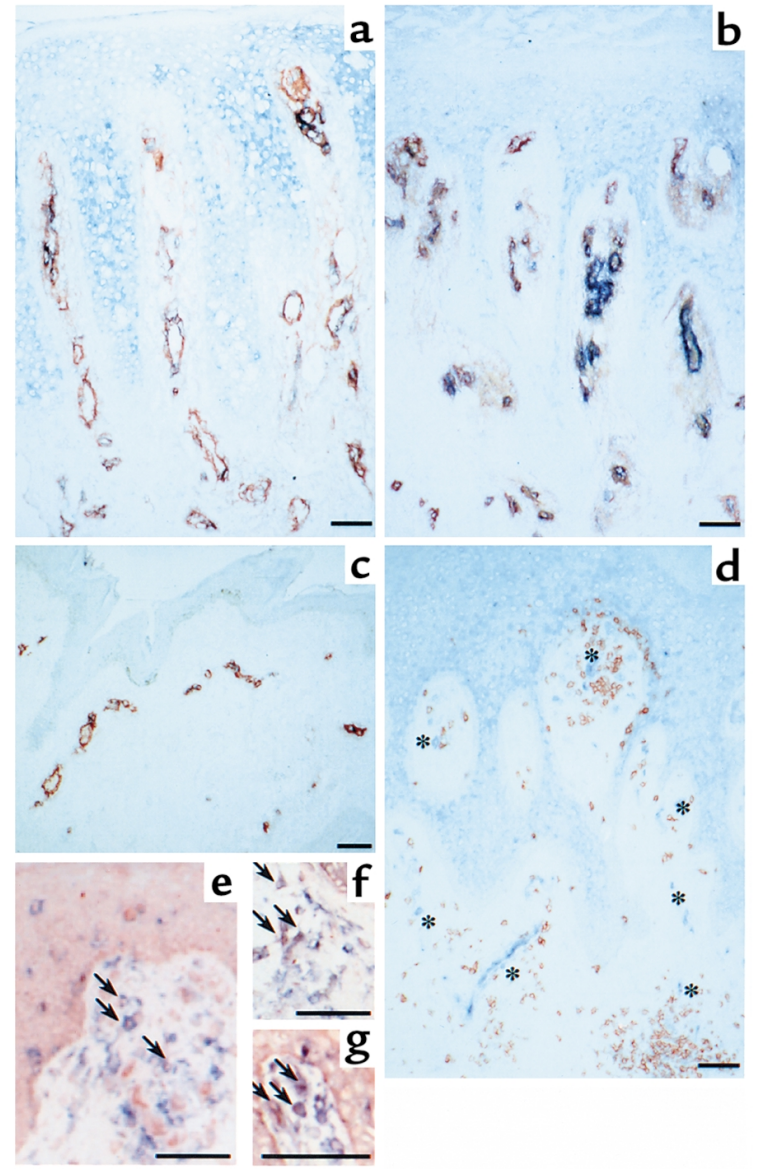

Figure 5

Detection of FKN and CX3CR1 in chronic lesions from psoriasis and atopic dermatitis. Sections from atopic dermatitis (a and $\mathbf{e}$ ) and psoriasis ( $\mathbf{b}, \mathbf{d}, \mathbf{f}, \mathbf{g}$ ) lesions and normal skin of healthy subjects (c) were double-stained for FKN (blue) and factor VIII (redbrown) (a-c) or CD3 (red-brown) (d), or for CX3CR1 (redbrown) and CD4 (blue) (e-g). Arrows in $\mathbf{e}-\mathbf{g}$ indicate the CX3CR1/CD4 double-positive cells; asterisks indicate FKN-positive vessels. Bars $=40 \mu \mathrm{m}$.

\section{Figure 6}

FKN and CX3CR1 immunostaining in M. tuberculosis granulomatous lymphadenitis. (a) AntiFKN immunostaining is confined to blood vessels and to a few scattered large dendritic-like cells of the paracortex. A faint staining is present also in scattered macrophages close to the necrotic area of the granuloma. (b) Double staining with CD34 (brown) shows that FKN (blue) is expressed by the ECs of a large number of paracortical vessels. (c) The large dendriticlike FKN-positive cells (blue) scattered in the paracortex were shown to be CD1a-positive (brown), newly migrated immature dendritic cells. (d) The positivity for CX3CR1 is present in the epithelioid macrophages of the granuloma and in cells with macrophage-like morphology and some lymphocyte-like cells in the paracortex. Double stained sections were not counterstained. (a, b, and d) $\times 250$; (c) $\times 400$.
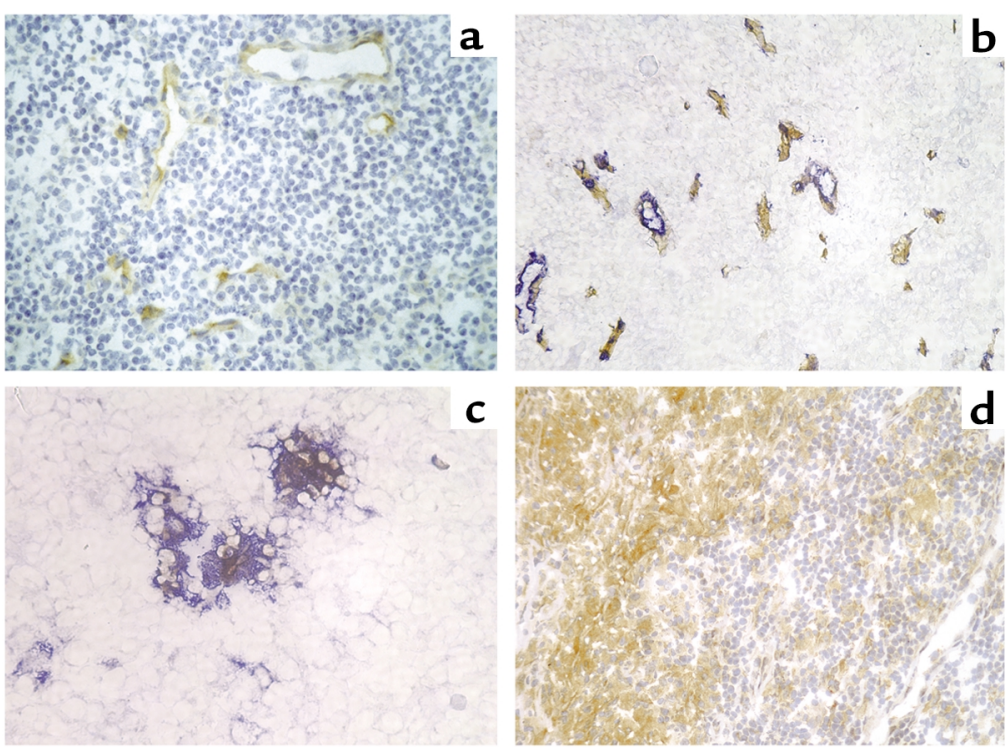
FKN was also detected in monocyte-derived dendritic cells in vitro (data not shown), thus extending previous reports $(46,47)$. Whether dendritic cell-expressed FKN is released and recruits other leukocytes or plays a role in lymphocyte-dendritic cell physical interactions remains to be ascertained.

The finding that IFN- $\gamma$ and IL-4/IL-13 have divergent effects on FKN expression in ECs prompted us to investigate the effect of FKN on NK cells and polarized $\mathrm{CD} 4^{+} \mathrm{T}$-cell populations. Previous studies have shown that the FKN receptor CX3CR1 is expressed on monocytes, $\mathrm{T}$ lymphocytes (naive and $\mathrm{CD} 8^{+}$cells, mainly), and NK cells $(6-9,38)$. In a recent study, Foussat et al. (50) have examined the expression of CX3CR1 in T-cell populations in terms of binding of $\mathrm{FKN}$-polyhistidinetagged recombinant protein, revealed with an antipolyhistidine $\mathrm{mAb}$. They found that, among $\mathrm{CD}^{+}$ cells, it was expressed mainly in $\mathrm{CD}^{2} 5 \mathrm{RO}^{+} \mathrm{T}$ cells as a functional receptor. Here we report that CX3CR1 is strongly expressed in NK cells and, at lower levels, in polarized Th1 cells, which respond chemotactically to FKN, unlike Th2 populations. Interestingly, engagement of the NK cell-activating receptor CD16 downregulated CX3CR1 expression. Along the same line, downregulation of mRNA CX3CR1 expression has been observed in $\mathrm{CD}^{+}$lymphocytes exposed to PHA (6) and in one preliminary experiment with Th1 cells stimulated with mAb's to $\mathrm{CD} 3 / \mathrm{CD} 28$ (data not shown). Hence, low expression of CX3CR1 in tissueinfiltrating cells may reflect downregulation in response to local activation signals. NK cells, by responding to IL- 12 and producing IFN- $\gamma$, take part in polarized Th1 responses $(23,24)$. Therefore the pattern of CX3CR1 expression and responsiveness in polarized T-cell populations and in NK cells mirrors the differential regulation of agonist (FKN) production in ECs by the polarizing cytokines IFN- $\gamma$ and IL-4/IL-13.

Polarized T-cell populations have different repertoires of chemokine receptors. Polarized Th1 cells express high levels of CCR 5 and functional CXCR3. In contrast, CCR 4 and CCR 8 are preferentially present on polarized Th2 cells $(14-16,20,21)$. This distinction is not absolute. For instance, T-cell activation induces CCR4 in polarized Th1 cells (20). The regulation of agonist production reflects the differential distribution of receptors. So, for instance, CXCR3 ligands are induced by IFN- $\gamma$ (3). Reciprocally, MDC is induced by IL-4/IL-13 and blocked by IFN- $\gamma(19)$. On this basis, it was hypothesized that chemokine-based circuits are important in the regulation of polarized responses $(2$, $20)$. The results reported here show that IFN- $\gamma$ and IL4/IL-13 have divergent effects on FKN expression and release in ECs and that, reciprocally, functional CX3CR1 is expressed strongly in NK cells and preferentially in polarized Th1 compared with Th2 cells. These observations suggest that FKN and its cognate receptor CX3CR1 are part of the chemokine-based amplification and orientation circuits of polarized Th1 responses. It may therefore represent a valuable target for blocking Th1-mediated responses such as acute allograft rejection, consistent with the recently reported increase in cardiac allograft survival in mice treated with antibodies to CX3CR1 (51).

It has been observed that HIV-infected patients homozygous for the CX3CR1 I-249 M280 allele show rapid progression to AIDS (52). The CX3CR1 I-249 M280 haplotype is associated with reduced affinity and surface expression of the receptor. Given the protective role of polarized Th1 responses against many opportunistic pathogens and HIV itself, it is tempting to speculate that the rapid progression to AIDS of CX3CR1 I-249 M280 homozygous individuals might depend on a defective capacity to mount fully effective type I responses.

\section{Acknowledgments}

This study was supported by special project AIDS (40C.59 and 30C.80); Istituto Superiore Sanità; IRCCS; EC Biomed Program (EC BMH4 CT98-3277 and CT98-2343); National Research Council Biotechnology Target Project; ex art 10 Legge 46; Fondazione Istituto Pasteur Cenci Bolognetti; MURST, Cofinanziamento; Associazione Italiana per la Ricerca sul Cancro. We thank Carla Paganin for NK cultures, Sergio Bernasconi for FACS analysis, and Andrea Iellem for help and discussions.

1. Rollins, B.J. 1997. Chemokines. Blood. 90:909-928.

2. Mantovani, A. 1999. The chemokine system: redundancy for robust outputs. Immunol. Today. 20:254-257.

3. Luster, A.D. 1998. Chemokines: chemotactic cytokines that mediate inflammation. N. Engl. J. Med. 338:436-445.

4. Bazan, J.F., et al. 1997. A new class of membrane-bound chemokine with a CX3C motif. Nature. 385:640-644.

5. Pan, Y., et al. 1997. Neurotactin, a membrane-anchored chemokine upregulated in brain inflammation. Nature. 387:611-617.

6. Imai, T., et al. 1997. Identification and molecular characterization of fractalkine receptor CX3CR1, which mediates both leukocyte migration and adhesion. Cell. 91:521-530.

7. Combadiere, C., Gao, J., Tiffany, H.L., and Murphy, P.M. 1998. Gene cloning, RNA distribution, and functional expression of mCX3CR1, a mouse chemotactic receptor for the CX3C chemokine fractalkine. Biochem. Biophys. Res. Commun. 253:728-732

8. Al-Aoukaty, A., Rolstad, B., Giaid, A., and Maghazachi, A.A. 1998. MIP3alpha, MIP-3beta and fractalkine induce the locomotion and the mobilization of intracellular calcium, and activate the heterotrimeric $\mathrm{G}$ proteins in human natural killer cells. Immunology. 95:618-624.

9. Fong, A.M., et al. 1998. Fractalkine and CX3CR1 mediate a novel mechanism of leukocyte capture, firm adhesion, and activation under physiologic flow. J. Exp. Med. 188:1413-1419.

10. Haskell, C.A., Cleary, M.D., and Charo, I.F. 1999. Molecular uncoupling of fractalkine-mediated cell adhesion and signal transduction. Rapid flow arrest of CX3CR1-expressing cells is independent of G-protein activation. J. Biol. Chem. 274:10053-10058.

11. Karpus, W.J., et al. 1997. Differential CC chemokine-induced enhancement of T helper cell cytokine production. J. Immunol. 158:4129-4136.

12. Gu, L., et al. 2000. Control of TH2 polarization by the chemokine monocyte chemoattractant protein-1. Nature. 404:407-411.

13. Aliberti, J., et al. 2000. CCR5 provides a signal for microbial induced production of IL-12 by CD8a ${ }^{+}$dendritic cells. Nat. Immunol. 1:83-87.

14. Sallusto, F., Mackay, C.R., and Lanzavecchia, A. 1997. Selective expression of the eotaxin receptor CCR3 by human T helper 2 cells. Science. 277:2005-2007.

15. Bonecchi, R., et al. 1998. Differential expression of chemokine receptors and chemotactic responsiveness of type $1 \mathrm{~T}$ helper cells (Th1) and Th2.J. Exp. Med. 187:129-134.

16. Zingoni, A., et al. 1998. The chemokine receptor CCR8 is preferentially expressed by Th2 but not Th1 cells. J. Immunol. 161:547-551.

17. Bonecchi, R., et al. 1998. Divergent effects of IL-4 and interferon gamma on macrophage-derived chemokine (MDC) production: an amplification 
circuit of polarized T helper 2 responses. Blood. 92:2668-2671.

18. Galli, G., et al. 2000. Macrophage-derived chemokine production by activated human $T$ cells in vitro and in vivo: preferential association with the production of type 2 cytokines. Eur. J. Immunol. 30:204-210.

19. Mantovani, A., Gray, P.A., Van Damme, J., and Sozzani, S. 2000. Macrophage-derived chemokine. J. Leukoc. Biol. 68:400-404.

20. D'Ambrosio, D., et al. 2000. Localization of Th-cell subsets in inflammation: differential thresholds for extravasation of Th1 and Th2 cells. Immunol. Today. 21:183-186.

21. Sallusto, F., Lanzavecchia, A., and Mackay, C.R. 1998. Chemokines and chemokine receptors in T-cell priming and Th1/Th2-mediated responses. Immunol. Today. 19:568-574.

22. Romagnani, S. 1997. The Th1/Th2 paradigm. Immunol. Today. 18:263-266

23. Trinchieri, G. 1998. Interleukin-12: a cytokine at the interface of inflammation and immunity. Adv. Immunol. 70:83-243.

24. Trinchieri, G. 1995. Natural killer cells wear different hats: effector cells of innate resistance and regulatory cells of adaptive immunity and of hematopoiesis. Semin. Immunol. 7:83-88.

25. Sozzani, S., et al. 1998. Cutting edge: differential regulation of chemokine receptors during dendritic cell maturation: a model for their trafficking properties. J. Immunol. 161:1083-1086.

26. Allavena, P., et al. 1991. Molecules and structures involved in the adhesion of natural killer cells to vascular endothelium. J. Exp. Med. 173:439-448.

27. Van Hinsbergh, V.W.M., Sprengers, E.D., and Kooistra, T. 1987. Effect of thrombin on the production of plasminogen activators and PA inhibitor1 by human foreskin microvascular endothelial cells. Thromb. Haemost. 57:148-153.

28. Allavena, P., et al. 1994. Induction of natural killer cell migration by monocyte chemotactic protein-1, -2 and -3 . Eur. J. Immunol. 24:3233-3236.

29. Jonjic, N., et al. 1992. Expression of adhesion molecules and chemotactic cytokines in cultured human mesothelial cells. J. Exp. Med. 176:1165-1174.

30. Sozzani, S., et al. 1997. Receptor expression and responsiveness of human dendritic cells to a defined set of CC and CXC chemokines. J. Immunol. 159:1993-2000.

31. Sozzani, S., et al. 1998. Interleukin-10 increases CCR5 expression and HIV infection in human monocytes. J. Exp. Med. 187:439-444.

32. Raport, C.J., et al. 1996. New members of the chemokine receptor gene family. J. Leukoc. Biol. 59:18-23.

33. Falk, W., Goodwin, R.H., Jr., and Leonard, E.J. 1980. A 48-well microchemotaxis assembly for rapid and accurate measurement of leukocyte migration. J. Immunol. Methods. 33:239-245.

34. Mantovani, A., Bussolino, F., and Introna, M. 1997. Cytokine regulation of endothelial cell function: from molecular level to the bed side. Immunol. Today. 18:231-239.

35. Sironi, M., et al. 1994. Regulation of endothelial and mesothelial cell function by interleukin-13: selective induction of vascular cell adhesion molecule- 1 and amplification of interleukin- 6 production. Blood 84:1913-1921.

36. Colotta, F., et al. 1992. Interleukin 4 amplifies monocyte chemotactic protein and interleukin 6 production by endothelial cells. Cytokine. 4:24-28.

37. Rollins, B.J., and Pober, J.S. 1991. Interleukin-4 induces the synthesis and secretion of MCP-1JE by human endothelial cells. Am. J. Pathol. 138:1315-1319.

38. Yoneda, O., et al. 2000. Fractalkine-mediated endothelial cell injury by NK cells. J. Immunol. 164:4055-4062.

39. Bos, J.D., and De Rie, M.A. 1999. The pathogenesis of psoriasis: immunological facts and speculations. Immunol. Today. 20:40-46.

40. Szabo, S.K., Hammerberg, C., Yoshida, Y., Bata-Csorgo, Z., and Cooper, K.D. 1998. Identification and quantitation of interferon-gamma producing T cells in psoriatic lesions: localization to both CD4+ and CD8+ subsets. J. Invest. Dermatol. 111:1072-1078.

41. Pastore, S., Fanales-Belasio, E., Albanesi, C., Chinni, L.M., and Girolomoni, G. 1997. Granulocyte macrophage colony-stimulating factor is overproduced by keratinocytes in atopic dermatitis: implications for sustained dendritic cell activation in the skin. J. Clin. Invest. 99:3009-3017.

42. Leung, D.Y. 2000. Atopic dermatitis: new insights and opportunities for therapeutic intervention. J. Allergy Clin. Immunol. 105:860-876.

43. Garcia, G.E., et al. 2000. NF-kappaB-dependent fractalkine induction in rat aortic endothelial cells stimulated by IL-1beta, TNF-alpha, and LPS. J. Leukoc. Biol. 67:577-584.

44. Orlando, S., et al. 1997. Role of the metalloproteases in the release of the IL-1 type II decoy receptor. J. Biol. Chem. 272:31764-31769.

45. Crowe, P.D., et al. 1995. A metalloprotease inhibitor blocks shedding of the $80-\mathrm{kD}$ TNF receptor and TNF processing in T lymphocytes. J. Exp. Med. 181:1205-1210.

46. Papadopoulos, E.J., et al. 1999. Fractalkine, a CX3C chemokine, is expressed by dendritic cells and is up-regulated upon dendritic cell maturation. Eur. J. Immunol. 29:2551-2559.

47. Kanazawa, N., et al. 1999. Fractalkine and macrophage-derived chemokine: $T$ cell-attracting chemokines expressed in $T$ cell area dendritic cells. Eur. J. Immunol. 29:1925-1932.

48. Harrison, J.K., et al. 1998. Role for neuronally derived fractalkine in mediating interactions between neurons and CX3CR1-expressing microglia. Proc. Natl. Acad. Sci. USA. 95:10896-10901.

49. Maciejewski-Lenoir, D., Chen, S., Feng, L., Maki, R., and Bacon, K.B. 1999. Characterization of fractalkine in rat brain cells: migratory and activation signals for CX3CR-1-expressing microglia. J. Immunol. 163:1628-1635.

50. Foussat, A., et al. 2000. Fractalkine receptor expression by T lymphocyte subpopulations and in vivo production of fractalkine in human. Eur. J. Immunol. 30:87-97.

51. Robinson, L.A., et al. 2000. A role for fractalkine and its receptor (CX3CR1) in cardiac allograft rejection. J. Immunol. 165:6067-6072.

52. Faure, S., et al. 2000. Rapid progression to AIDS in HIV+ individuals with a structural variant of the chemokine receptor CX3CR1. Science. 287:2274-2277 